\title{
A identidade no documentário Elena
}

Adriano Charles Cruz ${ }^{1}$

${ }^{1}$ Adriano Charles Cruz é jornalista, mestre em Comunicação e doutor em Letras. Professor do Programa de Pós-graduação em Artes Cênicas da Universidade Federal do Rio Grande do Norte. Atualmente, coordena o grupo de pesquisa CiCult - Círculo de Estudo em Cultura Visual. 


\title{
Resumo
}

$\mathrm{Na}$ modernidade líquida, as identidades estão em constante crise. A partir desse pressuposto, analisamos a construção discursiva da identidade no documentário Elena (2012), de Petra Costa. O filme é marcado pelo hibridismo entre o real e o ficcional e pela enunciação de mulheres, protagonistas dessa narrativa. Defendemos a hipótese de que a identidade é tecida nos jogos de memória dos sujeitos em tela.

Palavras-chave: identidade; memória; documentário.

\begin{abstract}
In "Liquid Modernity", identities are in constant crisis. From this assumption, we analyze the discursive construction of identity in the documentary Elena (2012), Petra Costa. The film is marked by hybridity between the real and the fictional and the enunciation of women protagonists of this narrative. We defend the hypothesis that the identity is woven in memory games of subjects.
\end{abstract}

Keywords: identity, memory, documentary. 


\section{Considerações iniciais}

A identidade está em crise na pós-modernidade, a solidez moderna se liquefez no hibridismo contemporâneo. As grandes certezas e os fundamentos sociais mais permanentes se dissolvem em uma época propícia às transformações. E mais: as identidades, agora cambiantes, se constroem a partir de uma perspectiva da visibilidade midiática. Nos jogos de memória dos sujeitos e do aparato técnico constroem-se discursividades de si e do outro, ou seja, processos identitários. Ao rememorar acontecimentos, pensamentos, sentimentos e emoções, os indivíduos vão se afirmando enquanto sujeitos singulares.

Tateando essa era de hipervisibilidade e espetacularização, identificamos no documentário contemporâneo pistas simbólicas para se compreender a formação identitária por meio do discurso.

Elegemos como norteador de nossa reflexão uma narrativa documental calcada no relato da história de vida de uma mulher encenado em frente às câmeras. O documentário brasileiro Elena (2012), de Petra Costa, é marcado pelo hibridismo entre o real e o ficcional e pela enunciação de mulheres, protagonistas desses discursos.

A questão que nos suscita pode ser elaborada nos seguintes termos: como a identidade das "personagens" é construída sob a instabilidade da memória na modernidade liquida?

Entendemos que as imagens no aparato cinematográfico são recortes de um construto de realidade ou uma ficcionalização desses elementos que buscam parecer verossímeis, sobretudo, no documentário.

A partir da definição desse problema, delineamos como objetivo a análise da construção identitária da narradora-personagem-diretora no filme em tela. Para isso, discutiremos algumas enunciações e cenas nas quais Petra Costa atualiza e reconstrói a memória familiar no processo fílmico².

\footnotetext{
${ }^{2}$ A singularidade reside na narrativa autobiográfica e nos múltiplos papeis desenvolvidos por Petra Costa (diretora, narradora, atriz e roteirista do filme). Ela estreou como diretora de cinema, em 2009,
} 
Em Elena, primeiro longa-metragem da diretora, temos a carta de uma irmã viva para uma morta, narrativa recriada com imagens reais e antigas de uma câmera caseira e sons em fita cassete, gravados ao longo dos anos pela irmã mais velha, que se suicida em 1990. Essa tragédia, também desenvolvida com imagens cinematográficas profissionais, é o fio condutor da narrativa que mescla elementos ficcionais com a jornada real de três mulheres, costuradas pelo destino e pela pulsão de morte: as irmãs Elena, Petra e mãe delas.

Buscamos analisar como se desenham as identidades femininas a partir da construção dessas memórias autobiográficas ou autoficcionais.

Ao analisar as identidades femininas pós-modernas, à luz de um documentário híbrido, resvalamos na questão fulcral do cinema como um sistema de representação de mundo e de construção da realidade.

O termo repraesentare significa, etimologicamente, tornar presente uma abstração em um objeto ou por meio dele. Ao emergir como tentativa de representação da realidade, o cinema documental, a partir dos Lumières, minimizou os efeitos da morte. Se a fotografia representava o instante final (BARTHES, 1981), as imagens em movimento mobilizariam a roda da memória, perpetuando a presença dos representados ${ }^{3}$.

A adoção da estética ficcional afronta a barreira do documentário. Essas fronteiras deslocadas e errantes tornam cada vez mais verdadeira a afirmação de que o cinema é um construto complexo de representações, conforme afirmou Godard "[...] nem arte, nem técnica, um mistério.". (GODARD, 1998, p. 182).

Se as identidades são cambiantes, o gênero documentário assim também se apresenta em Elena. No documentário, com sua vontade de verdade, as fronteiras entre o representado e imaginário fílmico se confrontam e promovem questões de ordens filosóficas, estéticas e existenciais. Ao permitir a encenação, Petra Costa

com o curta Olhos de Ressaca, no qual também utiliza a história de familiares como fio condutor da narrativa.

${ }^{3} \mathrm{Em}$ Elena esse simulacro da presença provoca uma expectativa de que a protagonista ainda estaria viva. 
desestabiliza o efeito mimético documental, recurso possível e executável no contexto histórico da pós-modernidade.

O rompimento das fronteiras clássicas entre ficcional e real se consolidou no documentário brasileiro a partir de uma série de realizadores. A estética ficcional como afronta às normas do documentário tem em Eduardo Coutinho ${ }^{4} \mathrm{o}$ mais contundente representante. Em Jogo de Cena (2006), o hibridismo entre a ficção e a realidade forma um jogo cênico que combina elementos ficcionais a partir de histórias reais e desconstrói o gênero, problematizando os seus limites e as suas fronteiras. Elena herda essa filiação histórica, os jogos narrativos levam a um processo de estranhamento do documentário, lembro as questões feitas na primeira sessão: como essas imagens reais foram gravadas? Qual o sentido de se encenar a vida no cinema?

Esse procedimento estético nos permite extrapolar a máxima de Zizek (2003, p. 26), quando desvela a construção do realismo nos reality shows: "[...] ainda que se apresentem como reais para valer, as pessoas que neles aparecem estão representando - representam a si mesmas.".

Em Elena (2012) essa autorrepresentação se exacerba na tessitura da narrativa: imagens filmadas em vida pela irmã morta se mesclam com a narrativa em off e a representação de seu drama familiar. O papel da mãe, personagem central do documentário, se amalgama com a encenação de atrizes na cena final. A dança nas águas mistura bailarinas profissionais com as personagens do documentário produzindo um efeito palimpsesto e intericônico ${ }^{5}$.

Para Ramos (2008) essas narrativas documentárias que se revelam "ardilosamente" ficções não invalidam as definições do que é documentário, stricto sensu. Concordamos com a afirmativa, mas pressupomos que nesses momentos estamos próximos à noção de acontecimento, entendido como a irrupção de uma

\footnotetext{
${ }^{4} \mathrm{O}$ autor se destaca pelos documentários Santo Forte (1999), Babilônia 2000 (2001), Edifício Master (2004) e Jogo de Cena (2007).

${ }^{5}$ Intericonicidade é o processo de diálogo e ressignificações das imagens no funcionamento da memória. Nesta cena, é impossível não se evocar à pintura Ofélia de John Everett Millais.
} 
singularidade única e aguda, no lugar e no momento de sua produção (FOUCAULT, 2004). Esse acontecimento documental pós-moderno nos permite adentrar de maneira inovadora na análise da identidade feminina.

\section{Identidades em costuras}

A crise da identidade é um acontecimento da "modernidade líquida". Segundo Bauman (2013), o estágio atual da modernidade é marcado por instabilidade de todas as ordens; o autor alude à metáfora do Manifesto Comunista para explicar esse processo:

'Dissolver tudo que e sólido' tem sido a característica inata e definidora da forma de vida moderna desde o principio; mas hoje, ao contrário de ontem, as formas dissolvidas não devem ser substituídas (e não o são) por outras formas sólidas consideradas 'aperfeiçoadas', no sentido de serem até mais sólidas e 'permanentes' que as anteriores, e portanto até mais resistentes à liquefação. No lugar de formas derretidas, e portanto inconstantes, surgem outras, não menos - se não mais suscetíveis ao derretimento, e portanto também inconstantes. (BAUMAN, 2013, p. 16, grifos do autor).

Em obra anterior, Bauman (2005) defende que, durante séculos, as relações sociais se mantiveram no domínio da proximidade. A construção artificial dos territórios permitiu um senso de pertença à localidade que dava sentido aos habitantes. Naquelas condições, a identidade era evidente demais para ser um problema, posto que calcada na proximidade geográfica, nos domínios da localidade; todavia, quando o poder aglutinador da vizinhança se reduz a identidade, emerge como desafio.

A identidade na contemporaneidade não seria mais essa "coisa concreta", mas, nem por isso, inexistente. É possível pensá-la na construção narrativa de Elena como elemento aberto e em formação, como revela a diretora Petra Costa que, após ler os diários da irmã na adolescência, ficara completamente identificada com 
as memórias escritas. "Ali decidi um dia fazer um filme sobre este tema da crise de identidade entre as irmãs.". (COSTA, 2014).

$\mathrm{Na}$ modernidade líquida (BAUMAN, 2005), há uma série de "identidades" inventadas ou à disposição dos sujeitos. Esse processo constrói-se antes do nascimento e perpassa os espaços e dispositivos sociais. Bauman (2005, p. 83) advoga que a identidade é um "[...] conceito altamente contestado" Essa afirmação nos leva a pressupor que a construção de uma persona social e o reconhecimento de si como parte de um grupo se dá no enfrentamento com a alteridade, como no caso do filme que analisamos. É somente ao investigar as memórias de e sobre Elena que Petra Costa consegue se desidentificar com a irmã.

Essas proposições refletem a importância da análise da construção identitária no documentário Elena. E mais: as narrativas são elementos inquietantes para se compreender os atores numa época de descentramento, hibridismo, paradoxos e mal estar, característica destes tempos.

Todo processo identitário é construído nos espaços da memória e da lembrança. Halbwachs (2004) advoga que, por meio da memória, o passado vem à tona, misturando-se com as percepções imediatas, deslocando-as, ocupando todo o espaço da consciência. Se a lembrança é de ordem subjetiva, a memória é social, formada por pensamentos e experiências coletivas imbricadas. Dessa forma, as lembranças de Petra Costa são assomadas a elementos construtores de memória: os arquivos escolares e médicos, os diários da irmã, o testemunho dos familiares, o retorno aos lugares em que ela viveu.

Entendemos que as lembranças dos indivíduos são construídas, reconfiguradas, encenadas dentro do grupo social de seus atores e do momento histórico de sua produção. E nem sempre esse processo é pacífico, há lutas e resistências para os discursos memorialísticos. Sarlo (2007) nos lembra que o passado é sempre conflituoso e que é impossível reprimi-lo; enquanto existirem os sujeitos que viveram os acontecimentos, as lembranças pessoais e coletivas persistem: 
não ser que se eliminem todos os sujeitos que o carregam [...]. Em condições subjetivas e políticas "normais", o passado sempre chega ao presente. (SARLO, 2007, p. 10, grifos da autora).

Esse conflito se evidencia quando a família de Petra Costa tenta apagar as memórias da irmã o que, paradoxalmente, corrobora com o processo de investigação da diretora. O percurso de construção de sua identidade/alteridade levará a narradora-cineasta a reconstruir tais fragmentos interditados a partir dos objetos pessoais, discursos e imagens de Elena. Assim, esse exemplo aponta-nos a força do passado que "[...] continua ali, longe e perto, espreitando o presente como a lembrança que irrompe no momento em que menos se espera ou como a nuvem insidiosa que ronda o fato do qual não se quer ou não se pode lembrar.". (SARLO, 2007, p. 9).

A partir da "modernidade líquida" houve um ressurgimento do "espetáculo do passado", conforme aponta Sarlo (2007), com a ênfase na criação de objetos culturais (filmes, livros, espetáculos etc.) e monumentos que tencionam construir passagens históricas. Antes, era impensável a produção de um documentário, com financiamento público e privado, sobre a história de uma mulher anônima, posto que os grandes acontecimentos e temas sociais eram privilegiados: "Esses sujeitos marginais, que teriam sido relativamente ignorados em outros modos de narração do passado, demandam novas exigências de método e tendem à escuta sistemática dos "discursos de memória": diários, cartas, conselhos, orações." (SARLO, 2007, p. 17, grifos da autora).

Toda história de vida está inscrita em corpos de sujeitos desejantes, partidos pela fragmentação existencial de si. O inconsciente, como linguagem e processo, aponta a falta como condição da subjetividade humana. Nesse sentido, através da arte, Petra ressignifica a sua relação com a irmã, conforme declarou em entrevista: "ao longo do filme, Elena foi virando um ser humano, de carne e osso, com diversas características. $\mathrm{O}$ processo era como se eu constantemente estivesse ganhando uma irmã para em seguida perdê-la de novo.". (COSTA, 2014).

Defendemos que a palavra no documentário funciona como phármakon e mobiliza a ação das depoentes. O perder e reencontrar a irmã produz efeitos 
dolorosos, mas ressignifica a lacuna do "outro", conforme declarou a diretora na referida entrevista:

Foi uma mistura de prazer e dor. A parte prazerosa foi que ganhei uma irmã neste processo, já que tinha poucas lembranças da Elena por ser muito pequena e a via meio como uma lenda. Ao mesmo tempo a dor foi muito grande porque tinha muito mais consciência para entender o que realmente aconteceu e o quão trágico foi. (COSTA, 2014).

É no jogo da memória, calcado na configuração social e coletiva, com a lembrança, pessoal e subjetiva, traduzido no falar das personagens, construção simbólica, que o processo identitário vai se conformando.

\section{No emaranhado da memória, as fraturas identitárias}

A identidade construída e encenada é produto relativo e provisório da história de vida e das condições históricas e sociais. Em frente às câmeras, os sujeitos ressignificam suas falas e produzem discursividades distintas do cotidiano, seja pela exploração dos recursos técnicos (closes, câmera na mão, imagens desfocadas, saturação das cores, planos abertos, iluminação impressionista) ou por outros elementos dramatúrgicos (flashback, narração em primeira pessoa, depoimentos, inserção de imagens reais, fotografias e documentos) que dão uma atmosfera memorialística e poética à narrativa.

Acerca desse aspecto, Petra declarou que Elena se aproxima do curta Olhos de Ressaca (2009), primeiro trabalho dela como diretora: "onde (eu) havia descoberto esta estética mais onírica e poética, (de) que havia gostado bastante. É também uma forma de falar da memória e do sonho, usando bastante material em Super 8, película, 16mm e VHS.". (COSTA, 2014). Fica explícita a adoção de uma estética híbrida que explora as reminiscências pessoais de maneira realística, a partir de imagens não profissionais, e a estética poética, evidenciada na direção de arte, na sonoplastia e na fotografia. 
A identidade, sempre dinâmica, precisa de um sujeito que represente para si e para o outro uma maneira de se colocar no mundo, seja por suas atividades, discursos e memórias recontadas. Há diferentes maneiras dessas "personagens" construírem seus lugares de fala e suas apropriações da memória. Em Elena a narração subjetiva evoca pertencimento e produz efeitos de proximidade e intimidade, ouvimos as memórias de Petra como se lêssemos os seus pensamentos e sondássemos suas emoções. Se rememorar no documentário é sempre ocasião de escolhas, cortes e supressões, a memória no filme está, como as irmãs, fraturada no limite do campo cinematográfico ${ }^{6}$.

O postulado da alteridade como estruturante da identidade é ponto pacífico nas ciências humanas, mas é sempre bom reafirmar que o sujeito sempre negocia com o Outro suas identificações e desidentificações. É o que ocorre no processo de redescoberta e reconstrução das memórias de Elena.

O caráter dinâmico de identidade/alteridade leva-nos à análise das personagens de Elena. Quem, afinal, são Petra e Elena Costa? Como elas se constituem em diferentes subjetividades, apesar dos mesmos desejos profissionais, amor à atuação, doença mental e desejo de morte?

Só temos acesso a esses sentidos a partir da fala como materialidade da memória e das rememorações. É nesse plano do simbólico que intentamos tatear o funcionamento dessas imagens documentais. Dessa forma, procedemos um recorte no plano das falas das personagens, embora reconheçamos que outros elementos narrativos (música, enquadramentos, edição, luz, etc.) cooperam na produção de sentidos. Há um efeito narrativo a ser esclarecido: Petra sempre se dirige à Elena no presente como se ela pudesse ouvi-la. Para o espectador, gera uma expectativa de que Elena está viva até o momento da revelação do seu suicídio.

A construção narrativa do filme da diretora-enunciadora permite um discurso que reforça o amálgama identitário das personagens femininas, ao rememorar uma fala do pai - talvez, o primeiro a identificar (ou construir) tais semelhanças:

\footnotetext{
${ }^{6}$ Essa constatação se torna mais clara na leitura dos offs da narradora.
} 
$\mathrm{Na}$ verdade, o nosso pai sempre disse que eu e você herdamos esse sonho de fazer cinema da nossa mãe. E no meio dessas fitas de vídeo, eu achei esse filme que ela nunca me mostrou. É um filme mudo em que ela interpreta a protagonista no tempo em que ela ainda sonhava em ser atriz de Hollywood e beijar o Frank Sinatra. Assim se sentia mulher e tentava escapar de um mundo em que se via desadaptada, incompreendida. Filha de uma tradicional família mineira, ela não viu um lugar para si. A não ser casada, mulher, society. (grifos nossos).

A identidade é sempre uma negociação entre o que os "outros" nos atribuem e aquilo que reconhecemos como nosso. Petra não apenas rememora o discurso do pai como também se identifica com ele, mais à frente no filme, ela enuncia: "Hoje eu ando pela cidade ouvindo sua voz e me vejo tanto em suas palavras que começo a me perder em você.". (grifos nossos).

O deslocamento, o sentindo de incompletude e vazio existencial marcarão passagens relevantes do discurso das três mulheres. A mãe, como Elena, deseja frustradamente ser atriz de cinema. Tais desejos não se realizam na vida da protagonista, apesar de convocada para vários testes em Nova lorque, onde morava, a efetivação do sonho não ocorre. Em off, Petra conta como a irmã contactava os produtores, levava fotos, currículo, entrevistas, mas não obtinha êxito: "[...]os dias passam e ninguém te dá notícia. Ninguém liga de volta. Você liga muitas vezes, mas te dizem para esperar. Você não suporta esse tempo. Essa espera...".

Sem conseguir lidar com a frustração profissional e existencial, a personagem sucumbe ao suicídio.

Em diversos momentos, o documentário põe em destaque os elementos biográficos que aproximam as duas irmãs. No início, Petra narra um sonho recorrendo à metáfora do emaranhado ${ }^{7}$, na qual depreendemos as profundas identificações das duas:

\footnotetext{
${ }^{7}$ Eliane Brum no artigo "Petra, uma mulher em busca do próprio corpo", escrito para a Revista Época, destacava esta comparação metafórica.
} 
No universo onírico, linguagem inconsciente por excelência, a autoria das ações é dividida entre Petra e Elena, como elemento indicativo das identidades móveis e em construção. A narração de Petra agudiza a dramaticidade da narrativa, aos poucos o espectador percebe os sentimentos envolvidos nas relações: a morte precoce da irmã deixa a pequena Petra, então com sete anos, perturbada, por isso, será levada ao acompanhamento médico para diagnóstico e tratamento. Os sintomas neuróticos da filha mais nova surgem a partir da consciência efetiva da efemeridade humana e, com isso, o medo da perda da mãe. "Começo a fazer promessas constantes. Que não vou comer mais sal, que vou subir todas as escadas do nosso décimo nono andar de joelhos, que nunca mais vou me olhar no espelho para ela não morrer.".

O caminho de Petra, treze anos mais nova que a irmã, é o da identificação especular, quando adolescente, aspira ao sonho interditado pela família: torna-se atriz. De certa maneira, esse "sonho" fora construído por Elena, conforme depreendemos do fragmento: "minha mãe disse que você, desde os quatro anos, sabia que queria ser atriz. E parece que você sempre dava um jeito de me pôr para contracenar com você.". Depois disso, Elena exibe imagens da atriz e multiartista americana Shirley Temple e "[...] me treina para ser atriz", conclui a rememoração.

Novamente, a identidade das duas se conecta: duas irmãs, duas atrizes. Entre elas, o pesadelo da depressão e o medo materno de que a filha mais nova se encaminhe para a autodestruição. "Nossa mãe sempre me disse que eu podia morar em qualquer lugar do mundo, menos Nova lorque. Que eu podia escolher qualquer profissão, menos ser atriz.".

Contrariando a interdição materna, Petra ingressa no curso de teatro em Nova lorque. A proteção familiar tenta construir um apagamento da imagem da irmã morta, mas o resultado é inócuo. A filha caçula encaminha-se aos EUA, com os 
pertences da irmã, para Ihe reconstruir uma memória, enturvada pelo tempo: "queriam que eu te esquecesse, Elena, mas eu volto para Nova lorque na esperança de encontrar você nas ruas. Trago comigo tudo que você deixou no Brasil".

Petra não se mata, torna-se atriz e diretora de cinema, e constrói pelo discurso uma ponte entre Elena e si. É nesse processo que se dá o afastamento das duas e a consolidação de outra identidade para a irmã mais nova, rompe-se o emaranhado e Petra se consolida como "outra". Esse processo de busca de investigação da voz da irmã possibilita a transformação da realizadora-narradora:

\footnotetext{
O medo de seguir seus passos começou a se desfazer. Eu comecei a perceber que você, Elena, estava dentro de mim, querendo estar em mim. Deixei de sentir isso, a começar a te buscar. Você foi, ganhou forma e corpo renascendo para mim, mas para morrer de novo. E eu com muito mais consciência para sentir sua morte dessa vez, imenso prazer acompanhado da dor. Eu me afogo em você e em Ofélias. (grifos nossos).
}

Ao fim da narrativa, a diretora-realizadora realiza o grande desejo da visibilidade, transforma a irmã e a mãe em personagens do próprio documentário. $\mathrm{Na}$ tomada final, há um rio onde dançarinas profissionais, ao lado de Petra e mãe, encenam o suicídio de si e da mãe num mar e num balé de Ofélias. Ao reconstruir os desejos de vida e morte, ela transforma a memória distante de Elena num ritual de renascimento, ao que conclui: "eu enceno. Enceno a nossa morte. Para encontrar ar. Para poder viver. Pouco a pouco as dores viram água, viram memória." Em seguida, destaca indelevelmente a ação da memória: "as memórias vão com o tempo. Se desfazem. Algumas não encontram consolo. Apenas um alívio. Encontram brecha na poesia. Você é minha memória inconsolável. Feita de sombra e pedra. E dela que tudo nasce e dança.".

E termina o filme com o "sob o som" da música Dedicated To The One I Love, do Mamas e Papas, cujo fragmento, traduzimos: "toda noite, antes de você ir para cama, baby/ Sussurre uma oração por mim, baby/E diga a todas as estrelas acima:/essa é dedicada a quem eu amo". 


\section{Considerações Finais}

Encenar as memórias enturvadas pelo tempo é reconstruir a si mesma pelo fazer fílmico, como faz a cineasta, antropóloga de formação. Petra realiza uma etnografia de si mesma e de seu entorno, conectando-se com os espíritos que povoam o imaginário familiar. Ela exorciza o espectro do "outro" a partir da constituição fílmica, pública e hiper-real. A vida pós-moderna não pode ser apenas vivida, é preciso publicizá-la para os outros. Para contar esse drama "verdadeiro", à semelhança das contadoras de histórias, a diretora recorre ao ficcional e à reconstrução poética, desafiando limites dos gêneros fílmicos.

Desde a sua gênese, por meio do legado dos precursores como Mèlies e Griffith, o cinema já se constrói um campo de experimentações entre a ficção e o real. Essas experimentações chegam às imagens hiper-realistas - cujas câmeras perscrutam toda a vida, pensamento e ação das personagens - do final do século passado e à ruptura da estética clássica do cinema documental que tem em Elena um expoente. O que torna o filme singular é o foco subjetivo da narradorapersonagem e tom autobiográfico, autoficcional e memorialístico.

A recepção favorável da crítica - foram mais de nove prêmios em festivais - e do público - foi o documentário mais visto no Brasil em 2013 - se ancora nas mudanças históricas de produção e circulação dos produtos culturais. Nas últimas décadas, houve uma revalorização do interesse pelas micronarrativas do cotidiano. E, nesse esteio, volta-se a atenção para as histórias de vidas. Nessa "guinada subjetiva" (SARLO, 2007), processo de enriquecimento da memória na reconstrução do passado, valorizam-se os relatos, o testemunho e os discursos dos sujeitos que viveram in loco os acontecimentos.

Os discursos em Elena podem nos levar ao equívoco de pensar que as relações de identidade/alteridade das personagens são um processo apenas subjetivo e biográfico. Acreditamos que os processos históricos - condições de existência - permitiram a ressignificação dos sujeitos em tela. Entendemos que há três grandes processos intrínsecos à narrativa: a ênfase na subjetividade, ou seja, o fortalecimento individual dos protagonistas da história, independente de sua 
posição no grupo social; a aceitação da ruptura das normais clássicas formais e a hipervisibilidade contemporânea e o esgarçamento da construção da realidade.

Só foi possível produzir um documentário sobre uma biografia de uma anônima graças ao processo contemporâneo de estetização do cotidiano, como apontam os reality-shows, homens comuns rompem a barreira da invisibilidade e encenam suas vidas diante das câmeras. Já se defendeu que, a partir da pós-modernidade, os grandes mitos e as grandes narrativas abrem espaço para as falas do dia-a-dia, para os discursos menores e para a celebração do indivíduo.

É sintomático que o filme enfoque a vida e o desejo de uma atriz, profissional que, em tempo da hegemonia dos mass media, sobretudo, nos anos de 1980 , quando se passa a história, tem como grande meta o desejo de entrar no star system. As questões de história de vida tocam o seio da sociedade capitalista, o sonho hollywoodiano de Elena também é comungado por inúmeras atrizes ao redor do mundo.

As narrativas autoficcionais pululam no cotidiano: blogs, redes sociais, livros e filmes popularizam a publicação dessas histórias. O voyerismo e o narcisismo complementam esse sucesso. Todos nós continuamos a olhar pelas frechas das fechaduras, sejam elas construídas em madeira ou pixels.

Outra questão importante a se ponderar: na hegemonia do mass media, o hiper-realismo suplanta o real e se coloca como pressuposto da verdade; por exemplo, não importa a informação da morte de Elena, é preciso ouvir os depoentes, exibir o laudo médico, detalhar as reações da mãe em planos, zooms e câmera lenta. A partir desse pressuposto de hiper-realismo das estéticas cinematográficas contemporâneas, podemos generalizar a hipótese de Aumont (1999, p. 70): “[...] todo filme é um filme de ficção.". 


\section{Referências}

AUMONT, J. Esthétique du film. Paris: Nathan, 1999

BARTHES, Roland. A câmara clara. Lisboa: 70, 1981.

BAUMAN, Zygmunt. Identidade: entrevista à Benedetto Vecchi. Rio de Janeiro: Zahar, 2005.

A cultura no mundo líquido moderno. Rio de Janeiro: Zahar, 2013.

COSTA, Petra. Entrevista exclusiva. Petra Costa fala sobre o documentário Elena. Disponível em: http://www.adorocinema.com/noticias/filmes/noticia-102960/. Acesso em 20 de março de 2014.

FOUCAULT, Michel. A arqueologia do saber. 7. ed. Rio de Janeiro: Forense Universitária, 2004.

GODARD, Jean-Luc. Histoire(s) du cinema. Paris : Gallimard-Gaumont , 1998.

HALL, Stuart. A identidade cultural na pós-modernidade. 10 ed. Rio de Janeiro: DP\&A, 2005.

HALBWACHS, Maurice. A memória coletiva. São Paulo: Vértice, 2004.

RAMOS, Fernão Pessoa. Mas afinal...o que é mesmo documentário? São Paulo: SENAC, 2008.

SARLO, Beatriz. Tempo passado: cultura da memória e guinada subjetiva. São Paulo: Companhia das Letras; Belo Horizonte: UFMG, 2007.

ZIZEK, Slavoj. Bem-vindo ao deserto do real: cinco ensaios sobre o 11 de setembro e datas relacionadas. São Paulo: Boitempo Editorial, 2003. 